\title{
miR-1975 serves as an indicator of clinical severity upon influenza infection
}

\author{
Yuag-Meng Liu ${ }^{1,2} \cdot$ Hui-Chen Chen $3,4,5 \cdot Y i-C h u n C^{2}{ }^{2} \cdot$ Wen-Ya Yu ${ }^{6} \cdot$ Meng-Yen Ho ${ }^{6} \cdot$ Chia-Yin $\mathrm{Ho}^{6}$. \\ Michael M.C. Lai ${ }^{5,6,7} \cdot$ Wen-Chi Su ${ }^{1,5,6}$
}

Received: 12 March 2020 / Accepted: 11 August 2020 / Published online: 19 August 2020

(C) Springer-Verlag GmbH Germany, part of Springer Nature 2020

\begin{abstract}
Emerging evidence highlights the role of non-coding small RNAs in host-influenza interaction. We have identified a Y RNAderived small RNA, miR-1975, which is upregulated upon influenza A virus infection in A549 cells. The aim of this study is to investigate whether miR-1975 serves as an indicator of clinical severity upon influenza infection. We investigate the abundance of miR-1975 in sera from clinical patients and its correlation with hypoxemia status. We quantified its amounts in sera from influenza virus-infected patients and healthy volunteers by means of stem-loop RT-PCR. Median values of miR-1975 were significantly higher in influenza virus-infected patients, especially in hypoxemic patients. miR-1975 levels at the acute stage of the disease were highly correlated with the fraction of inspired oxygen used by the patients and total ventilator days. Receiver operator characteristic curve analysis revealed that miR-1975 levels in combination with days of fever before presenting to hospital had significant predictive value for hypoxemia and respiratory failure for patients infected with influenza virus. Our results reveal that circulating miR-1975 has great potential to serve as a biomarker for predicting prognosis in patients infected with influenza virus.
\end{abstract}

Keywords Influenza virus $\cdot$ Y RNA $\cdot \operatorname{miR}-1975 \cdot$ Biomarker

\section{Introduction}

Influenza virus causes annual endemic diseases and worldwide outbreaks. It poses a considerable threat to both human health and the global economy [1]. An estimated 270,000

Wen-Chi Su

t23514@mail.cmuh.org.tw

1 Graduate Institute of Clinical Medical Science, China Medical University, Taichung, Taiwan

2 Division of Infectious Diseases, Changhua Christian Medical Foundation, Changhua Christian Hospital, Changhua, Taiwan

3 Department of Microbiology and Immunology, School of Medicine, China Medical University, Taichung, Taiwan

4 Research and Development Center for Immunology, China Medical University, Taichung, Taiwan

5 Graduate Institute of Biomedical Sciences, China Medical University, Taichung, Taiwan

6 Research Center for Emerging Viruses, China Medical University Hospital, Taichung, Taiwan

7 Institute of Molecular Biology, Academia Sinica, Taipei, Taiwan people died of pandemic $2009 \mathrm{~A} / \mathrm{H} 1 \mathrm{~N} 1$ influenza virus, and some patients have become resistant to currently available anti-influenza viral medication during therapy $[2,3]$. Some influenza virus strains can invade epithelial cells of the lungs. Subsequently, immune cells are recruited. Overproduction of inflammatory mediators occupies alveolar space and contributes to lung damage, as well as respiratory failure [4]. Patients present with severe hypoxemia and mechanical ventilation is warranted [5]. A detailed understanding of the host-influenza relationship would provide a means for better prevention of the spread of influenza virus and decrease morbidities and mortalities in hypoxemic patients.

Small RNAs such as microRNA (miRNA) have been found to play vital roles in host-influenza interaction [6-9]. We recently reported that another class of small RNA, Y RNA-derived small RNA, is indispensable in a host's response upon influenza virus infection [10]. Small RNAs are found in intracellular loci and encapsulated in exosomes that prevent them from degradation by RNases in extracellular space $[10,11]$. Sera from patients are easy to access in comparison with lung tissue, in patients who present with respiratory failure. Upregulation of several small RNAs in sera have been demonstrated in previous literature $[12,13]$. However, 
there is no comprehensive understanding of the biogenesis and functions of these small RNAs.

We have demonstrated that miR-1975, a Y5 RNA-derived small RNA, is the most upregulated small RNA upon A/WSN/ 33 influenza virus infection in A549 cell through small RNA deep sequencing [10]. Our evidence indicates that miR-1975 is derived from Y5 during apoptosis [10]. It is secreted into exosomes and restricts influenza virus replication via stimulating interferon production [10]. In the current study, we corroborated the importance of this small RNA in patients who contracted influenza virus. We demonstrated the enhanced detection of miR-1975 in sera of influenza virus-infected patients. Levels of several small RNAs have been demonstrated to change when patients suffered from infectious diseases [12, 14]. However, there is no evidence that they are positively correlated with the extent of hypoxemia in humans with severe influenza pneumonia. Here, we adopted the fraction of inspired oxygen (FiO2) used by the patients to determine clinical severity and revealed that the level of miR-1975 serves as a marker for clinical severity of the disease.

\section{Materials and methods}

\section{Human subjects}

All protocols involving the collection, handling, and laboratory use of sera were approved by the IRB committee of Changhua Christian Hospital. All participants were adults. Thirty patients were confirmed to have influenza infection by rapid influenza antigen test or PCR of their nasopharyngeal specimens. Serial dilutions of synthetic miR-1975 were used to generate a standard equation to quantify the amount of miR1975 in patients $\left(R^{2}=0.9954\right)$. Serum samples from nine healthy volunteers were used as controls. The following patients were excluded from the study: (a) patients below 20 years old, (b) patients above 100 years old, (c) pregnant women, (d) patients who refused to sign informed consents, (e) patients who were unconscious, (f) patients who were infected with other pathogens in addition to the influenza virus, and $(\mathrm{g})$ patients with malignancy.

\section{Quantitative RT-PCR}

Cellular RNA was extracted by using a High Pure RNA Isolation Kit (Roche Diagnostics). SuperScript III FirstStrand Synthesis System (Invitrogen) was used to create cDNA. Real-time PCR analysis was performed by standard TaqMan method using the Universal Probe Library System (Roche Diagnostics). Stem-loop RT-PCR method was used to quantify small RNA, including miR-1975 and U24. Sequences for specific primers were mentioned in our previous study [10].

\section{Exosome isolation from human sera}

We thawed frozen sera on ice, and $100 \mu \mathrm{L}$ of serum was centrifuged at $3000 \mathrm{~g}$ twice to remove cells and cell debris. About $25 \mu \mathrm{L}$ of ExoQuick was mixed with the supernatant, and then incubated at $4{ }^{\circ} \mathrm{C}$ for $30 \mathrm{~min}$. We centrifuged the sample at $1500 \mathrm{~g}$ for $30 \mathrm{~min}$, removed the supernatant and resuspended the exosome pellet in $50 \mu \mathrm{L}$ of PBS.

\section{RNases treatment}

To ascertain that small RNAs were encapsulated within the exosomes rather than in contaminants on the outside of exosomes, we treated samples with RNase before proceeding with further experiments. We diluted exosome pellets in $50 \mu \mathrm{L}$ PBS and added Ambion RNase cocktail $2.5 \mu \mathrm{L}$ at $37^{\circ} \mathrm{C}$ for $15 \mathrm{~min}$.

\section{Western blotting analysis}

We purchased HSP70, CD63 and TSG101 from Genetex (no. GTX11573, GTX1744, and GTX10255). Cell lysates were obtained by using M-PER mammalian protein extraction reagent (Thermo Scientific) and electrophoretically transferred onto a Hybond-P membrane. The membrane was probed with the specific primary and secondary antibodies. Images were captured by an enhanced chemiluminescence detection kit and Image-Quant LAS4000.

\section{Statistics}

Quantitative variables were compared by Spearman correlation analysis, Mann-Whitney $U$ test, one-way ANOVA, Student's $t$ test, Wilcoxon signed rank test, or unconditional $z$-pooled test, as appropriate. For all analyses, a $P$ value below 0.05 was considered statistically significant for two-tailed tests. The SPSS (SPSS Inc., Chicago, IL, USA) was used for statistical analysis except for the unconditional $z$-pooled test, which was done using the software http:// www4.stat.ncsu.edu/ boos/exact/. The differentiation power to predict whether patients would develop hypoxemia and the requirement of mechanical ventilation was assessed by receiver operating characteristics (ROC) and area under the receiver operating characteristic curve (AUC). To evaluate the level of miR-1975 in predicting hypoxemia and the necessity of mechanical ventilation, we plotted ROC curves by means of binary logistic regression models with adjustment for several variants. Continuous variables were chosen if there were statistical correlations to hypoxemia, as depicted in Table $1(p<0.1)$. We generated six regression models. Age was adjusted in model 1. Age and CRP were adjusted in model 2. Age and days of fever before presenting to the hospital were 
Table 1 Demographic and baseline clinical characteristics of the participants

\begin{tabular}{|c|c|c|c|c|}
\hline & All & Hypoxemic & $\begin{array}{l}\text { Non- } \\
\text { hypoxemic }\end{array}$ & $P$ value \\
\hline Characteristic & $(n=30)$ & $(n=19)$ & $(n=11)$ & \\
\hline Age, years, mean \pm SD & $53.07 \pm 19.59$ & $62.26 \pm 14.24$ & $39.55 \pm 20.37$ & $0.001 *$ \\
\hline Sex, $n(\%)$ & & & & $0.85^{* *}$ \\
\hline Male & $18(60.0)$ & $11(57.9)$ & $7(63.6)$ & \\
\hline Female & $12(40.0)$ & $8(42.1)$ & $4(36.4)$ & \\
\hline Fever $\left(>38{ }^{\circ} \mathrm{C}\right), n(\%)$ & & & & $0.777 * *$ \\
\hline No & $4(13.3)$ & $3(15.8)$ & $1(9.1)$ & \\
\hline Yes & $26(86.7)$ & $16(84.2)$ & $10(90.9)$ & \\
\hline Days of fever, mean \pm SD & $6.08 \pm 7.10$ & $7.94 \pm 8.47$ & $3.10 \pm 2.13$ & $0.047 *$ \\
\hline Cough, $n(\%)$ & & & & $0.932 * *$ \\
\hline No & $1(3.3)$ & $1(5.3)$ & $0(0)$ & \\
\hline Yes & $29(96.7)$ & $18(94.7)$ & $11(100)$ & \\
\hline Days of cough, mean $\pm \mathrm{SD}$ & $6.03 \pm 6.75$ & $7.53 \pm 7.86$ & $3.45 \pm 3.08$ & $0.113 *$ \\
\hline Dyspnea & & & & $<0.001 * *$ \\
\hline No & $8(26.7)$ & $0(0)$ & $8(72.7)$ & \\
\hline Yes & $22(73.3)$ & $19(100)$ & $3(27.3)$ & \\
\hline Days of dyspnea, mean \pm SD & $5.91 \pm 7.21$ & $7.53 \pm 7.86$ & $3.45 \pm 3.08$ & $0.519 *$ \\
\hline Hospitalization days, mean $\pm \mathrm{SD}$ & $16.65 \pm 14.73$ & $19.5 \pm 15.37$ & $6.40 \pm 4.72$ & $0.078 *$ \\
\hline Corticosteroid use, $n(\%)$ & & & & $0.322 * *$ \\
\hline No & $21(70.0)$ & $12(63.2)$ & $9(81.8)$ & \\
\hline Yes & $9(30.0)$ & $7(36.8)$ & $2(18.2)$ & \\
\hline Diabetes mellitus, $n(\%)$ & & & & $0.454 * *$ \\
\hline No & $28(93.3)$ & $17(89.5)$ & $11(100)$ & \\
\hline Yes & $2(6.7)$ & $2(10.5)$ & $0(0)$ & \\
\hline Hypertension, $n(\%)$ & & & & $0.454 * *$ \\
\hline No & $28(93.3)$ & $17(89.5)$ & $11(100)$ & \\
\hline Yes & $2(6.7)$ & $2(10.5)$ & $0(0)$ & \\
\hline Coronary artery disease, $n(\%)$ & & & & $0.454 * *$ \\
\hline No & $28(93.3)$ & $17(89.5)$ & $11(100)$ & \\
\hline Yes & $2(6.7)$ & $2(10.5)$ & $0(0)$ & \\
\hline Congestive heart failure, $n(\%)$ & & & & $0.454 * *$ \\
\hline No & $28(93.3)$ & $17(89.5)$ & $11(100)$ & \\
\hline Yes & $2(6.7)$ & $2(10.5)$ & $0(0)$ & \\
\hline End stage renal disease, $n(\%)$ & & & & $0.235 * *$ \\
\hline No & $29(96.7)$ & $19(100)$ & $10(90.9)$ & \\
\hline Yes & $1(3.3)$ & $0(0)$ & $1(9.1)$ & \\
\hline $\mathrm{WBC}, /$ cumm, mean $\pm \mathrm{SD}$ & $9000 \pm 4368$ & $9346 \pm 4338$ & $8340 \pm 4578$ & $0.565^{*}$ \\
\hline $\mathrm{AST}, \mathrm{IU} / \mathrm{dL}$, mean $\pm \mathrm{SD}$ & $68.35 \pm 139.69$ & $47.94 \pm 38.45$ & $114.25 \pm 250$ & $0.480 *$ \\
\hline $\mathrm{ALT}, \mathrm{IU} / \mathrm{dL}$, mean $\pm \mathrm{SD}$ & $59.14 \pm 125.534$ & $43.34 \pm 29.09$ & $87.74 \pm 250.15$ & $0.527 *$ \\
\hline Creatinine, $\mathrm{mg} / \mathrm{dL}$, mean $\pm \mathrm{SD}$ & $1.34 \pm 1.20$ & $1.37 \pm 1.12$ & $1.29 \pm 1.41$ & $0.872 *$ \\
\hline $\mathrm{CRP} \mathrm{mg} / \mathrm{sL}$, mean $\pm \mathrm{SD}$ & $7.56 \pm 7.08$ & $8.43 \pm 3.20$ & $3.43 \pm 1.31$ & $0.096^{*}$ \\
\hline
\end{tabular}

*P value was calculated by Student's $t$ test

$* * P$ value was calculated by unconditional $z$-pooled test adjusted in model 3. Age and miR-1975 were adjusted in model 4. Age, days of fever before presenting to the hospital, and CRP were adjusted in model 5. Age, days of fever before presenting to the hospital, and miR-1975 levels were adjusted in model 6. The correlations between miR-1975 levels and the fraction of inspired oxygen ( $\mathrm{FiO} 2)$ used by the patients, total ventilator days, or total hospitalization days were analyzed using Spearman's correlation. 


\section{Results}

\section{Abundance of miR-1975 in sera of influenza-infected patients were not affected by hemolysis}

To assess whether the abundance of miR-1975 is enhanced in clinical infection, sera from 30 influneza virus-infected patients were collected from February to April in 2016 according to the protocol approved by the Institutional Review Board of Chuaghua Christian Hospital. Sera from all hospitalized patients were collected on admission day. For hypoxemic patients, another serum sample was collected when they had recovered from hypoxemia. For patients with mild symptoms who did not need hospitalization, sera were collected once at the outpatient department. Seven patients had mild symptoms and did not admit to hospital. Twenty-three patients were hospitalized, and 14 patients subsequently received mechanical ventilation. Sputum form hospitalized patients was sent for Gram staining and bacterial culture. Patients infected with other pathogens were excluded. We also excluded cancer patients because serum levels of miR-1975 have been found to be elevated in cases of various cancers [15-18]. To ensure that the quality of the samples was not compromised by hemolysis, we determined the ratio of miR-451a to miR-23a in each serum sample, since miR-451a is enriched in red blood cells, whereas miR-23a is enriched in cancer cells, relatively stable in serum, and unaffected by hemolysis $[19,20]$. The deltaCt values (the difference in threshold cycles between miR-23a-3p and miR-451a) of less than 5 are indicative of the samples being at less than $0.001 \%$ risk of hemolysis [21]. The deltaCt values of all sera in this study were all below $5(2.29 \pm 1.28)$, indicating that the abundance of small RNA in sera was not affected by hemolysis.

\section{Levels of miR-1975 in sera of influenza-infected patients}

We found that levels of miR-1975 in sera were significantly higher in the influenza infected patients as compared with healthy volunteers. Median values of miR-1975 in the healthy volunteers and patients were 14 and 246 molecules per nanoliter, respectively $(p<0.001$, by Mann-Whitney $U$ test) (Fig. 1a). Among 30 patients, 24 were infected with H1N1 influenza A virus and 6 patients were infected with Victoria lineage influenza B virus. There was no significant difference in levels of miR-1975 between patients infected with influenza A and influenza B virus ( 245 vs. 248 mol per nanoliter; $p=0.35$, by Mann-Whitney $U$ test). To examine whether the abundance of miR-1975 is correlated with severity of disease, we divided 30 patients into two groups. Classification as hypoxemic patients indicated that these patients presented with hypoxemia on admission day and received oxygen therapy. Non-hypoxemic patients, in contrast, presented with mild symptoms and did not need supplemental oxygen. Sixteen influenza A virus-infected patients and three influenza B virus-infected patients presented with hypoxemia. Baseline demographic and clinical characteristics of the two groups of patients are presented in Table 1. The symptoms reported in Table 1 represent symptoms on admission day for those who were admitted to the hospital. As for patients with mild symptoms who were not admitted to hospital, they reported symptoms in their outpatient department visit. Hypoxemic patients were hospitalized at a medium of 7 days post symptom onset and non-hypoxemic patients visited the hospital at a medium of 3 days post symptom onset. Non-hypoxemic patents might have been hospitalized or treated at the outpatient department. Hypoxemic patients had an older mean age, higher
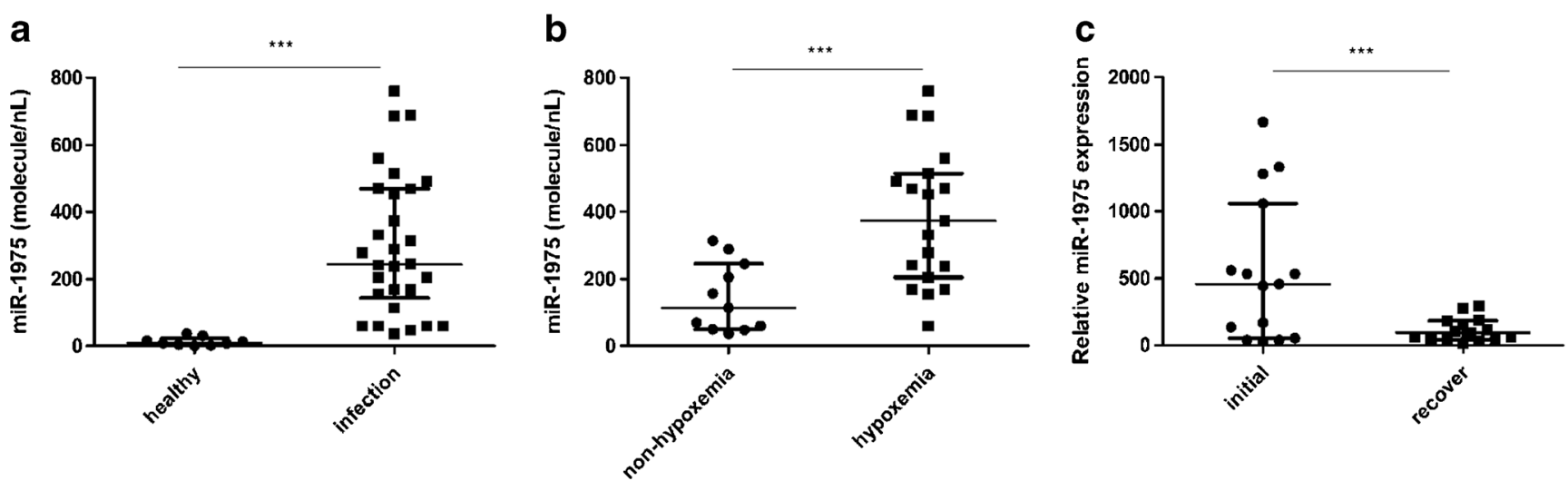

Fig. 1 Levels of miR-1975 in human serum. a miR-1975 levels in healthy volunteer control group $(n=9)$ versus patients diagnosed with influenza infection group $(n=30)$. b miR-1975 levels in influenzainfected patients who did not need oxygen therapy $(n=19)$ versus influenza-infected patients who presented with hypoxemia on admission day and received oxygen therapy $(n=11)$. c Relative miR-1975 levels in influenza-infected patients who were admitted to hospital. miR-1975 molecules were measured on admission day (initial) and on the day when patients recovered from fever and hypoxemia (recover). Statistical comparisons between groups by Mann-Whitney $U$ test (a and b) and Wilcoxon signed rank test (c). Data are expressed as miR-1975 molecules per nanoliter of serum. The bottom, middle, and top horizontal lines represent the $25 \%$ percentile, the median, and the $75 \%$ percentile of the data, respectively. $* * * P<0.001$ 
incidence of dyspnea, and longer duration of fever before visiting the hospital. They were prone to coughing for longer duration before presenting to the hospital, longer hospitalization stays (counted in days), and higher baseline levels of C-reactive protein (CRP) but not at levels achieving statistical significance. Baseline sex, incidence of fever and cough, use of corticosteroids, comorbidities of diabetes mellitus, hypertension, coronary artery disease, congestive heart failure, end stage renal disease and clinical laboratory measurements of white cell count, and liver and renal function were similar between the hypoxemic and nonhypoxemic groups. A comparison of miR-1975 levels in sera collected at the time of admission between these two groups of patients revealed a more significant upregulation of miR-1975 in hypoxemic patients. The medians of the miR-1975 levels in hypoxemic patients and nonhypoxemic patients were 410 and 205 molecules per nanoliter, respectively ( $p<0.01$, by Mann-Whitney $U$ test) (Fig. 1b). We found that serum miR-1975 levels at the acute stage of the disease were highly correlated with the fraction of inspired oxygen (FiO2) used by the patients (correlation coefficient $=0.663 ; p=0.001$, by Spearman's correlation) and total ventilator days (correlation coefficient $=0.545$; $p=0.008$, by Spearman's correlation). There is a weaker positive correlation between serum miR-1975 levels and total hospitalization days (correlation coefficient $=0.450$; $p=0.053$, by Spearman's correlation). Serum miR-1975 levels returned to nearly normal values when patients recovered from fever and hypoxemia $(p<0.01$, by Wilcoxon signed rank test) (Fig. 1c).

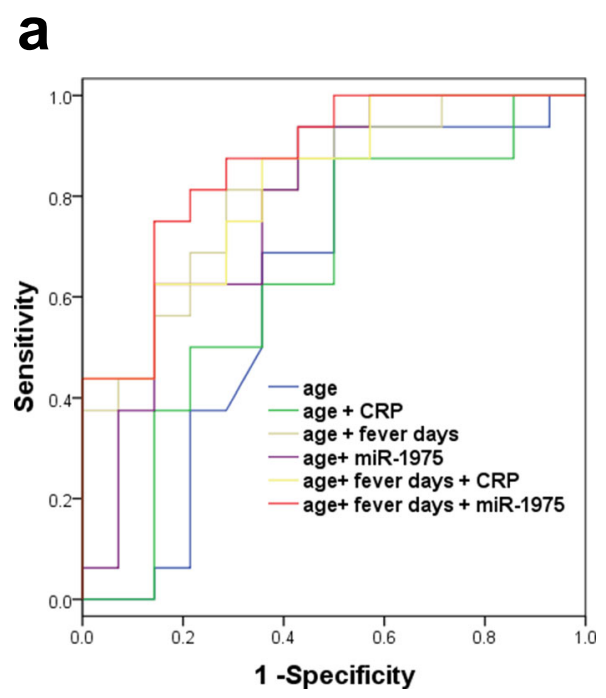

Fig. 2 Differentiating power of miR-1975 levels and days of fever for predicting hypoxemic status in patients with influenza infection. a Receiver operator characteristic (ROC) curves with $\mathbf{b}$ corresponding area under the curves (AUCs) for comparing the ability of miR-1975 and days of fever before admission to differentiate hypoxemic patients form non-
miR-1975 levels predict hypoxemic status in patients with influenza infection

We found hypoxemic patients presented with significantly higher serum miR-1975 levels and longer duration of fever when seeking medical help (Table 1; Fig. 1b). Next, we demonstrated the differentiation power of these factors by constructing receiver operator characteristic (ROC) curves (Fig. 2a). We used logistic regression models to adjust age for CRP, miR-1975 levels, and days of fever before visiting the hospital. Model 1 consisted of age only. The area under ROC curve (AUC) of this model was 0.634 (95\% CI 0.417 to $0.851, p=0.212$ ) (Fig. 2b). After adding CRP, days of fever and serum miR-1975 levels to model 1, the AUC was increased to 0.643 ( $95 \%$ CI 0.435 to $0.851, p=0.183$ ), 0.813 ( $95 \%$ CI 0.660 to $0.965, p=0.004$ ), and 0.786 (95\% CI 0.615 to $0.957, p=0.008$ ), respectively (Fig. $2 b$ ). After combining age, days of fever, and CRP, the AUC was 0.821 (95\% CI 0.674 to $0.969, p=0.003$ ). When combining age, days of fever, and serum miR-1975 levels, the AUC reaches 0.866 (95\% CI 0.732 to $0.995, p=0.001$ ), suggesting that high miR-1975 levels and prolonged fever are good indicators to predict hypoxemia in patients infected with influenza virus in comparison with CRP.

\section{miR-1975 levels predict respiratory failure in patients with influenza infection}

In addition, we investigated the value of miR-1975 levels in predicting whether mechanic ventilation is warranted

b

\begin{tabular}{|c|c|c|c|c|}
\hline & \multirow[b]{2}{*}{ AUC } & \multirow[b]{2}{*}{ p-value } & \multicolumn{2}{|c|}{$95 \% \mathrm{Cl}$} \\
\hline & & & $\begin{array}{c}\text { lower } \\
\text { limit }\end{array}$ & $\begin{array}{l}\text { upper } \\
\text { limit }\end{array}$ \\
\hline age & 0.634 & 0.212 & 0.417 & 0.851 \\
\hline $\begin{array}{l}\text { age + } \\
\text { CRP }\end{array}$ & 0.643 & 0.183 & 0.435 & 0.851 \\
\hline $\begin{array}{l}\text { age + } \\
\text { fever } \\
\text { days }\end{array}$ & 0.813 & 0.004 & 0.660 & 0.965 \\
\hline $\begin{array}{l}\text { age }+ \\
\text { miR-1975 }\end{array}$ & 0.786 & 0.008 & 0.615 & 0.957 \\
\hline $\begin{array}{l}\text { age + } \\
\text { fever } \\
\text { days + } \\
\text { CRP }\end{array}$ & 0.821 & 0.003 & 0.674 & 0.969 \\
\hline \begin{tabular}{|l} 
age + \\
fever \\
days + \\
miR-1975
\end{tabular} & 0.866 & 0.001 & 0.737 & 0.995 \\
\hline
\end{tabular}

hypoxemic patients. Four logistic regression models were postulated: (1) model 1: age, (2) model 2: model 1+CRP, (3) model 3: model 1+ days of fever before admission, (4) model 4: model 1+ miR-1975, (5) model 5: model $1+$ days of fever before admission + CRP, and (6) model 6: model $1+$ days of fever before admission + miR-1975 
(Fig. 3a). The area under ROC curve (AUC) of model 1, which included age only, was 0.603 (95\% CI 0.385 to $0.821, p=0.339$ ) (Fig. 3b). AUC slightly decreased to 0.571 (95\% CI 0.352 to $0.791, p=0.506$ ) after including age and CRP in model 2 (Fig. 3b). After adding days of fever and serum miR-1975 levels to the model 1, the AUC increased to 0.768 (95\% CI 0.597 to $0.939, p=0.013)$ and $0.772(95 \%$ CI 0.605 to $0.940, p=0.011$ ), respectively (Fig. 3b). After combining age, days of fever, and CRP, the AUC was 0.781 ( $95 \%$ CI 0.615 to $0.947, p=0.009$ ). When combining age, days of fever, and serum miR-1975 levels, the AUC reached 0.875 (95\% CI 0.75 to $1.000, p<0.001)$. All together, we identified serum miR-1975 levels as potential biomarkers to predict the extent of hypoxemia and whether patients would develop respiratory failure upon influenza virus infection, whereas CRP was a poor indicator here.

\section{miR-1975 is packaged into exosomes in influenza- infected patients}

Detection of miR-1975 molecules in patients' sera inferred that this small RNA may be released into extracellular fluid. Given that miR-1975 could be encapsulated in exosomes upon influenza virus infection in A549 cells [10], we next validated this finding in influenza-infected patients. To confirm this possibility, the exosome fractions were isolated from patients and characterized by Western blotting with specific

\section{a}

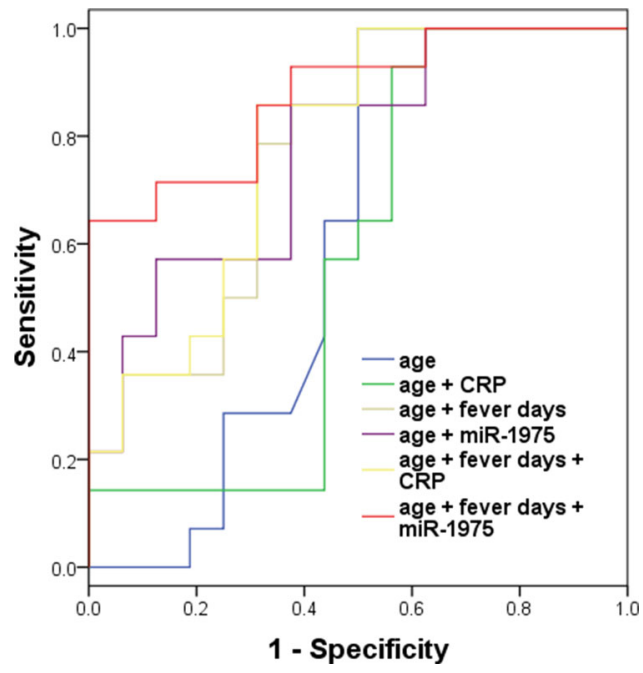

Fig. 3 Differentiating power of age combining with sex, miR-1975 levels or days of fever for necessity of mechanical ventilation in patients with influenza infection. a Receiver operator characteristic (ROC) curves with b corresponding area under the curves (AUCs) for comparing the ability of miR-1975 and days of fever before admission to differentiate hypoxemic patients form non-hypoxemic patients. Four logistic regression markers (Fig. 4a). The exosomal markers, including HSP70, CD63, and TSG101 [22], were detected in the isolated exosomes. Furthermore, the isolated exosomes had an average particle size of $48 \mathrm{~nm}$, as determined by dynamic light scattering (Fig. 4b), similar to that of classical exosomes. By detection of influenza viral RNA (vRNA) levels of NP segments using RT-PCR, we found no viral RNA could be detected in the isolated exosomes (data not shown). Exosome pellets were treated with RNase before RNA isolation to make sure that miR-1975 is contained within exosomes rather than in contaminants on the outside of exosomes. We quantified the levels of miR-1975 in exosomes. Interestingly, amounts of exosomal miR-1975 were significantly higher in influenza virus-infected patients than those in healthy volunteers (Fig. 4c). In addition, we also quantified the levels of miR-1975 in exosome-depleted supernatants. After calculation, we found $50.5 \%$ of serum miR-1975 molecules were captured in exosomes. Taken together, this evidence validated that miR1975 can be encapsulated in exosomes in serum.

\section{Discussion}

Non-coding sequences of human genomes account for $98.5 \%$ of all transcriptomes [23] and small non-coding RNAs comprise a large proportion of non-coding sequences. Previous literature mainly focused on microRNA. Here, we highlighted

b

\begin{tabular}{|c|c|c|c|c|}
\hline & \multirow[b]{2}{*}{ AUC } & \multirow[b]{2}{*}{ p-value } & \multicolumn{2}{|c|}{$95 \% \mathrm{Cl}$} \\
\hline & & & $\begin{array}{l}\text { lower } \\
\text { limit }\end{array}$ & $\begin{array}{c}\text { upper } \\
\text { limit }\end{array}$ \\
\hline age & 0.603 & 0.339 & 0.385 & 0.821 \\
\hline $\begin{array}{l}\text { age + } \\
\text { CRP }\end{array}$ & 0.571 & 0.506 & 0.352 & 0.791 \\
\hline $\begin{array}{l}\text { age + } \\
\text { fever } \\
\text { days }\end{array}$ & 0.768 & 0.013 & 0.597 & 0.939 \\
\hline $\begin{array}{l}\text { age + } \\
\text { miR- } \\
1975\end{array}$ & 0.772 & 0.011 & 0.605 & 0.940 \\
\hline $\begin{array}{l}\text { age + } \\
\text { fever } \\
\text { days + } \\
\text { CRP }\end{array}$ & 0.781 & 0.009 & 0.615 & 0.947 \\
\hline $\begin{array}{l}\text { age + } \\
\text { fever } \\
\text { days + } \\
\text { miR- } \\
1975\end{array}$ & 0.875 & $<0.001$ & 0.750 & 1.000 \\
\hline
\end{tabular}

models were postulated: (1) model 1: age, (2) model 2: model 1+ CRP, (3) model 3: model 1+ days of fever before admission, (4) model 4: model 1+ miR-1975, (5) model 5: model 1+ days of fever before admission + CRP, and (6) model 6: model 1+ days of fever before admission + miR1975 


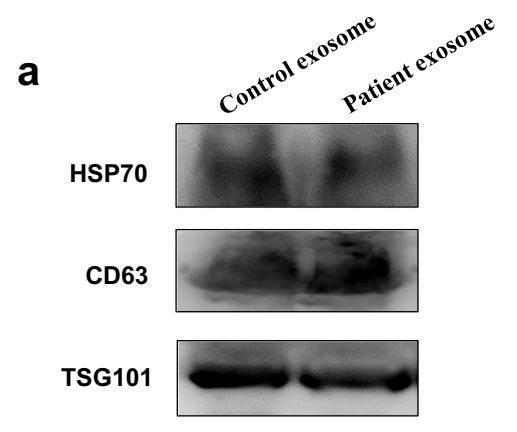

C

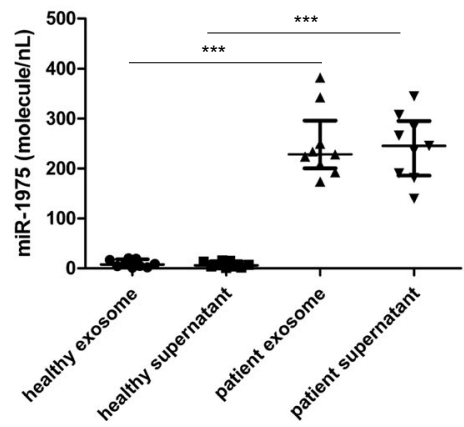

Fig. 4 miR-1975 is packaged into exosomes. a Characterization of exosomes by Western Blot analysis. Exosomes isolated from the patients were immunoblotted with the indicated antibodies. b Exosome pellets were diluted in $500 \mu \mathrm{L}$ PBS. Sizes of exosomes were determined by using the dynamic light scattering technique (Zetasizer Nano ZS,

the role of a less often mentioned small non-coding RNA, Y RNA-derived small RNA (YsRNA), in host response to influenza virus infection. Y RNAs are non-coding RNAs that play indispensable roles in DNA replication, RNA stability, and cellular stress responses [24]. Recent studies indicate that Y RNAs can be processed into small YsRNAs [25]. Since there is no sufficient evidence to prove these YsRNA function as miRNAs, they have been removed from miRBase, which is the primary database for miRNAs [25]. The biologic significance and signal pathways of YsRNA are not clearly elucidated yet [26]. Our group has showed that miR-1975, a YsRNA derived from Y5, exhibited antiviral properties through stimulating interferon production [10]. After demonstrating the impact of miR-1975 upon influenza infection in cells, this study focused on the levels of miR-1975 in clinical patients.

The amounts of miR-1975 in the serum were increased up to tenfold in influenza virus-infected patients, as compared with those in healthy volunteers (Fig. 1a). We demonstrated that hypoxemic influenza virus-infected patients exhibited higher amounts of serum miR-1975 than patients with milder symptoms who did not need oxygen therapy (Fig. 1b). None of the influenza-infected patients died in this cohort due to early aggressive supportive care including extracorporeal membrane oxygenation (ECMO) and mechanical ventilation. Expression profiles of small non-coding RNAs were reported to be altered in throat swabs or blood from influenza infected
Malvern Instruments, UK). The results of 6 repeats are shown. c Relative levels of miR-1975 in serum exosomes from healthy volunteers $(n=9)$ and influenza infected patients $(n=9)$ assessed by RT-qPCR. Statistical comparisons between groups by Student's $t$ test (c). $* P<0.05$

patients [27-31]. Among these published studies, Moran et al. was the only study group comparing amounts of circulating small non-coding RNAs from blood in mild influenza virusinfected patients to that in critically ill patients before our report [13]. They analyzed the expression of circulating miR-150 in healthy controls, household contacts, patients with mild disease, and patients with severe disease [13]. The relative expression levels assessed in household contacts and mild disease were similar. The abundance of miR-1975 was higher ( 1.5 fold) in patients on mechanical ventilation compared with those who did not develop respiratory failure [13]. They found the elevation of miR-150 is specific to H1N1 not to H3N2 in A549 cells [13]. We have reported that the elevation of miR1975 was not species-specific, as both H1N1 and H3N2 influenza virus induced upregulation of miR-1975 [10]. In the current study, levels of miR-1975 were doubled in hypoxemic patients compared with those with mild disease. This finding leads us to infer that miR-1975 reflects the stress patients suffer more closely than miR-150 does.

By correlating the levels of miR-1975 with the fraction of inspired oxygen used by the patients, we showed a strong association of miR-1975 with severity of influenza infection. Interestingly, the levels of serum miR-1975 on admission day are highly associated with ventilator days in severe influenza infected patients when mechanical ventilation was warranted. This further verified the role of serum miR-1975 levels as a 
novel prognostic tool in critically ill influenza infected patients. We alluded that miR-1975 may not be a suitable prognostic biomarker for other respiratory viruses because other common respiratory viruses rarely cause hypoxemia in patients. We have previously demonstrated that miR-1975 is encapsulated in exosomes secreted by A549 cells [10]. Here, we corroborated this phenomenon in vivo. This explains how miR-1975 avoids being degraded by RNases in sera.

We showed that miR-1975 induced interferon and inhibited influenza virus replication in our previous study [10]. Type I IFNs can recruit and activate immune cells, leading to lung inflammatory responses. Though virus burden can be controlled by this process, detrimental immunopathology occurs and then contributes to disease severity [32]. We showed miR-1975 levels were upgraded when apoptosis occurs in our previous work [10]. We speculated that the overwhelming interferon response induced apoptosis, and this may be the reason for larger amounts of miR1975 in hypoxemic patients. Cell apoptosis is prominent upon severe influenza virus infection [10]. We found that miR-1975 levels escalated in A549 cells upon influenza virus infection [10]. On the contrary, the amounts of miR-1975 did not significantly alter in E. coli-infected A549 or THP-1 cells (data not shown). This may be attributed to less apoptosis in cells upon bacterial infection compared with influenza virus infection. miR-1975 is encapsulated in exosomes when cells undergo apoptosis, and subsequently, exosomes are released into peripheral blood. These exosomes may trigger interferon or other responses in recipient cells.

The major limitation of this study is that the small sample size, as patient numbers were limited due to the rarity of critical influenza patients, admitted in a single hospital. Despite the patient number being limited, we still demonstrated that the amounts of miR-1975 in sera were statistically increased in influenza virus-infected patients, with these levels being clearly distinguishable between hypoxemic influenza virus-infected patients and non-hypoxemic patients with milder symptoms. Furthermore, we documented a strong association of miR-1975 with severity of disease and ventilator days in critically ill influenzainfected patients, which further verified miR-1975 levels as a prognosis marker in these patients. The correlation between miR-1975 and hospitalization days was weaker because some patients had longer lengths of stay due to comorbidity other than influenza virus infection.

In conclusion, our study supports the applicability of serum miR-1975 levels as a biomarker of clinical severity and predicting prognosis in patients who contracted influenza virus. In addition, we postulate miR-1975 is encapsulated in exosomes and upregulated in these patients. More studies are needed to unravel the biological and clinical implications of upregulation of miR-1975 in disease states in the future.
Funding Information The research described here is supported by Ministry of Science and Technology (MOST 105-2628-B-039-006MY3 to Wen-Chi Su, 106-2314-B-371-009-MY2 and 109-2314-B-371012 to Yuag-Meng Liu), China Medical University Hospital (CMU104TC-05 to Hui-Chen Chen) and Changhua Christian Hospital (107-CCHMST-011, 108-CCH-MST-153 and 108-CCH-IRP-007 to Yuag-Meng Liu)

\section{Compliance with ethical standards}

Conflict of interest The authors declare that they have no conflict of interest.

Ethical approval The study was approved by the ethical committee of Changhua Christian Hospital (IRB no. 151213) (Changhua, Taiwan). Each study participant (or their closest relative) voluntarily provided written informed consent prior to participating in the trial.

\section{References}

1. Lapinsky SE (2010) Epidemic viral pneumonia. Curr Opin Infect Dis 23:139-144. https://doi.org/10.1097/QCO.0b013e328336eaae

2. Memoli MJ, Hrabal RJ, Hassantoufighi A, Eichelberger MC, Taubenberger JK (2010) Rapid selection of oseltamivir- and peramivir-resistant pandemic $\mathrm{H} 1 \mathrm{~N} 1$ virus during therapy in $2 \mathrm{im}-$ munocompromised hosts. Clin Infect Dis 50:1252-1255. https:// doi.org/10.1086/651605

3. Dawood FS, Iuliano AD, Reed C, Meltzer MI, Shay DK, Cheng PY et al (2012) Estimated global mortality associated with the first 12 months of 2009 pandemic influenza A H1N1 virus circulation: a modelling study. Lancet Infect Dis 12:687-695. https://doi.org/10. 1016/S1473-3099(12)70121-4

4. Itoh Y, Shinya K, Kiso M, Watanabe T, Sakoda Y, Hatta M et al (2000) In vitro and in vivo characterization of new swine-origin H1N1 influenza viruses. Nature 460:1021-1025. https://doi.org/ 10.1038/nature08260

5. Lee N, Chan PK, Lui GC, Wong BC, Sin WW, Choi KW et al (2011) Complications and outcomes of pandemic 2009 Influenza A (H1N1) virus infection in hospitalized adults: how do they differ from those in seasonal influenza? J Infect Dis 203:1739-1747. https://doi.org/10.1093/infdis/jir187

6. Lam WY, Yeung AC, Ngai KL, Li MS, To KF, Tsui SK et al (2013) Effect of avian influenza A H5N1 infection on the expression of microRNA-141 in human respiratory epithelial cells. BMC Microbiol 13:104. https://doi.org/10.1186/1471-2180-13-104

7. Sun X, Feng W, Guo Y, Wang Q, Dong C, Zhang M et al (2018) MCPIP1 attenuates the innate immune response to influenza A virus by suppressing RIG-I expression in lung epithelial cells. J Med Virol 90:204-211. https://doi.org/10.1002/jmv.24944

8. Maemura T, Fukuyama S, Sugita Y, Lopes TJS, Nakao T, Noda T et al (2018) Lung-derived exosomal miR-483-3p regulates the innate immune response to influenza virus infection. J Infect Dis 217 : 1372-1782. https://doi.org/10.1093/infdis/jiy035

9. Preusse M, Schughart K, Pessler F (2017) Host genetic background strongly affects pulmonary microRNA expression before and during influenza A virus infection. Front Immunol 8:246. https://doi. org/10.3389/fimmu.2017.00246

10. Liu YM, Tseng CH, Chen YC, Yu WY, Ho MY, Ho CY (2019) Exosome-delivered and Y RNA-derived small RNA suppresses influenza virus replication. J Biomed Sci 26:58. https://doi.org/10. 1186/s12929-019-0553-6 
11. Turchinovich A, Weiz L, Langheinz A, Burwinkel B (2011) Characterization of extracellular circulating microRNA. Nucleic Acids Res 39:7223-7233. https://doi.org/10.1093/nar/gkr254

12. Zhu Z, Qi Y, Ge A, Zhu Y, Xu K, Ji H et al (2014) Comprehensive characterization of serum microRNA profile in response to the emerging avian influenza A (H7N9) virus infection in humans. Viruses 6:1525-1539. https://doi.org/10.3390/v6041525

13. Moran J, Ramirez-Martinez G, Jimenez-Alvarez L, Cruz A, PerezPatrigeon S, Hidalgo A et al (2015) Circulating levels of miR-150 are associated with poorer outcomes of A/H1N1 infection. Exp Mol Pathol 99:253-261. https://doi.org/10.1016/j.yexmp.2015.07.001

14. Barry SE, Ellis M, Yang Y, Guan G, Wang X, Britton WJ et al (2018) Identification of a plasma microRNA profile in untreated pulmonary tuberculosis patients that is modulated by antimycobacterial therapy. J Inf Secur 77:341-348. https://doi.org/10. 1016/j.jinf.2018.03.006

15. Dhahbi JM, Spindler SR, Atamna H, Boffelli D, Martin DI (2014) Deep sequencing of serum small RNAs identifies patterns of $5^{\prime}$ tRNA half and YRNA fragment expression associated with breast cancer. Biomark Cancer 6:37-47. https://doi.org/10.4137/bic. s20764

16. Meiri E, Levy A, Benjamin H, Ben-David M, Cohen L, Dov A et al (2010) Discovery of microRNAs and other small RNAs in solid tumors. Nucleic Acids Res 38:6234-6246. https://doi.org/10.1093/ nar/gkq376

17. Keller A, Leidinger P, Gislefoss R, Haugen A, Langseth H, Staehler $P$ et al (2011) Stable serum miRNA profiles as potential tool for non-invasive lung cancer diagnosis. RNA Biol 8:506-516. https:// doi.org/10.4161/rna.8.3.14994

18. Schotte D, Chau JC, Sylvester G, Liu G, Chen C, van der Velden $\mathrm{VH}$ et al (2009) Identification of new microRNA genes and aberrant microRNA profiles in childhood acute lymphoblastic leukemia. Leukemia 23:313-322. https://doi.org/10.1038/leu.2008.286

19. Blondal T, Jensby Nielsen S, Baker A, Andreasen D, Mouritzen P, Wrang Teilum $\mathrm{M}$ et al (2013) Assessing sample and miRNA profile quality in serum and plasma or other biofluids. Methods 59:S1-S6. https://doi.org/10.1016/j.ymeth.2012.09.015

20. Hu X, Wang Y, Liang H, Fan Q, Zhu R, Cui J et al (2017) miR-23a/ $\mathrm{b}$ promote tumor growth and suppress apoptosis by targeting PDCD4 in gastric cancer. Cell Death Dis 8:e3059. https://doi.org/ 10.1038/cddis. 2017.447

21. Shah JS, Soon PS, Marsh DJ (2016) Comparison of methodologies to detect low levels of hemolysis in serum for accurate assessment of serum microRNAs. PLoS One 11:e0153200. https://doi.org/10. 1371/journal.pone.0153200

22. Lotvall J, Hill AF, Hochberg F, Buzas EI, Di Vizio D, Gardiner C et al (2014) Minimal experimental requirements for definition of extracellular vesicles and their functions: a position statement from the International Society for Extracellular Vesicles. J Extracell Vesicles 3:26913. https://doi.org/10.3402/jev.v3.26913

23. Consortium EP, Birney E, Stamatoyannopoulos JA, Dutta A, Guigo R, Gingeras TR et al (2007) Identification and analysis of functional elements in $1 \%$ of the human genome by the ENCODE pilot project. Nature 447:799-816. https://doi.org/10.1038/ nature05874

24. Kowalski MP, Krude T (2015) Functional roles of non-coding $\mathrm{Y}$ RNAs. Int J Biochem Cell Biol 66:20-29. https://doi.org/10.1016/j. biocel.2015.07.003

25. Nicolas FE, Hall AE, Csorba T, Turnbull C, Dalmay T (2012) Biogenesis of Y RNA-derived small RNAs is independent of the microRNA pathway. FEBS Lett 586:1226-1230. https://doi.org/ 10.1016/j.febslet.2012.03.026

26. Chakrabortty SK, Prakash A, Nechooshtan G, Hearn S, Gingeras TR (2015) Extracellular vesicle-mediated transfer of processed and functional RNY5 RNA. Rna 21:1966-1979. https://doi.org/10. 1261/rna.053629.115

27. Chen X, Zhou L, Peng N, Yu H, Li M, Cao Z et al (2017) MicroRNA-302a suppresses influenza A virus-stimulated interferon regulatory factor-5 expression and cytokine storm induction. J Biol Chem 292:21291-21303. https://doi.org/10.1074/jbc.M117. 805937

28. Peng F, He J, Loo JF, Yao J, Shi L, Liu C et al (2016) Identification of microRNAs in throat swab as the biomarkers for diagnosis of influenza. Int J Med Sci 13:77-84. https://doi.org/10.7150/ijms. 13301

29. Song H, Wang Q, Guo Y, Liu S, Song R, Gao X et al (2013) Microarray analysis of microRNA expression in peripheral blood mononuclear cells of critically ill patients with influenza A (H1N1). BMC Infect Dis 13:257. https://doi.org/10.1186/1471-2334-13-257

30. Loo JF, Wang SS, Peng F, He JA, He L, Guo YC et al (2015) A non-PCR SPR platform using RNase $\mathrm{H}$ to detect MicroRNA 29a$3 p$ from throat swabs of human subjects with influenza A virus H1N1 infection. Analyst 140:4566-4575. https://doi.org/10.1039/ c5an00679a

31. Tambyah PA, Sepramaniam S, Mohamed Ali J, Chai SC, Swaminathan P, Armugam A et al (2013) microRNAs in circulation are altered in response to influenza $\mathrm{A}$ virus infection in humans. PLoS One 8:e76811. https://doi.org/10.1371/journal. pone. 0076811

32. Makris S, Paulsen M, Johansson C (2017) Type I interferons as regulators of lung inflammation. Front Immunol 8:259. https:// doi.org/10.3389/fimmu.2017.00259

Publisher's note Springer Nature remains neutral with regard to jurisdictional claims in published maps and institutional affiliations. 